\title{
Exploring the Influence of Sustainability Knowledge and Orientation to Slow Consumption on Fashion Leaders' Drivers of Fast Fashion Avoidance
}

\author{
Raye Carol Cavender*, Min-Young Lee \\ Department of Retailing and Tourism Management, University of Kentucky, Lexington, USA \\ Email address: \\ rayecarol.cavender@uky.edu (Raye C. C.), minyoung.lee@uky.edu (Min-Young L.) \\ ${ }^{*}$ Corresponding author
}

To cite this article:

Raye Carol Cavender, Min-Young Lee. Exploring the Influence of Sustainability Knowledge and Orientation to Slow Consumption on Fashion Leaders' Drivers of Fast Fashion Avoidance. American Journal of Theoretical and Applied Business.

Vol. 4, No. 3, 2018, pp. 90-101. doi: 10.11648/j.ajtab.20180403.12

Received: November 1, 2018; Accepted: November 28, 2018; Published: December 26, 2018

\begin{abstract}
This research explores the complex relationship between fashion leaders' motivations toward slow vs. fast fashion, and proposing that all consumers have the potential to adopt more sustainable consumption behaviors, offers suggestions for sustainable companies aiming to better understand and target these consumers. Fashion leaders are particularly susceptible to overconsumption, yet they are also the most attuned to fashion industry information (e.g., sustainability) and influence others through their tastes and preferences. Proposing that spurring fashion leaders toward slow consumption and away from fast fashion (FF) will prompt the spread of these trends among the broader consumer market, this exploratory study investigates how fashion leaders' level of sustainability awareness and orientation to slow consumption influence their FF avoidance. Primary data were collected from 405 respondents. Reliability and validity were examined through confirmatory factor analysis (CFA). Structural equation modeling (SEM) was used to analyze the data and parameters were estimated using maximum likelihood method. Empirical results from SEM show that sustainability awareness positively influences orientation to slow consumption yet does not influence the drivers of FF avoidance. The results indicate that consumers' orientation to slow consumption positively influences many FF avoidance drivers but data also suggest that fashion leaders may not characterize the FF business model as unsustainable and as fueling overconsumption. This study adds to the body of knowledge on highly fashion-involved consumers and their motivations toward sustainable consumption. It offers insight into the pro-environmental attitude-behavior gap and how these consumers reconcile their sustainability knowledge with their consumption desires. Past research has explored the impact of the pro-environmental attitude-behavior gap on consumers' purchase intentions. However, no empirical studies have been found that concurrently examine consumers' sustainability awareness, orientation to slow consumption, and their behavioral intention to avoid FF.
\end{abstract}

Keywords: Sustainability, Fast Fashion, Slow Consumption, Slow Fashion, Fashion Leaders

\section{Introduction}

According to the Environmental Protection Agency, in "less than 20 years, the volume of clothing Americans toss each year has doubled from 7 million to 14 million tons, or an astounding 80 pounds per person," with around $84 \%$ of unwanted clothing ending up in landfills [42]. It is not surprising that the dramatic increase in Americans' consumption and disposal of clothing has coincided with robust growth of fast fashion (FF) in the global retail market.
The significant waste and environmental impact of apparel production and distribution at the company-level, combined with overconsumption at the customer-level, is resulting in increasingly indisputable evidence of the environmental toll of the clothing industry. The environmental toll of FF and overconsumption will only intensify in the coming years as these retailers continue their expansion into emerging markets (e.g., India) and as consumers in those markets approach Western consumption levels [3, 12, 42].

In recent years, FF companies, to varying extents, have 
ramped up their commitments to sustainability within their supply chains, invested in R\&D for sustainable product innovation, and implemented internal compliance and reporting standards for assessing progress toward meeting annual objectives [42]. While these measures are commendable, they hardly offset the strain on natural resources (e.g., water) and pollution (e.g., dyeing, apparel waste) that result from the manufacturing process and are compounded by production volume [40]. More visible to the consumer, FF companies have introduced apparel-recycling programs, sustainably produced garments, and even entire sustainably produced lines such as H\&M's Conscious and Zara's Join Life Collection [12]. FF companies' efforts to position themselves as sustainable have resonated with consumers, yet critics often point out how this association is incredibly misleading as these efforts overshadow the two factors that make FF fundamentally unsustainable- speed and volume $[2,12,20]$.

A challenge now exists as the concept of sustainability "has been diluted by mass media companies/FF retailers to create a marketing buzzword out of it" [24]. Research suggests that such corporate greenwashing allows FF brands to continue exploiting consumers' (e.g., fashion leaders) desire for the new while limiting exposure to messages that could increase their awareness of the environmental impact of their own consumption behaviors [7, 15, 30]. That is, corporate greenwashing shapes consumer perceptions of sustainability by positioning it as a responsibility managed by the company (e.g., good labor conditions, use of renewable resources) while downplaying the impact of consumers' unsustainable consumption behaviors [7, 30].

The prevailing culture of overconsumption has recently been called into question, evidenced by the emergence of movements such as slow fashion [7, 30]. Slow fashion, a counter movement to the consumption practices that support the FF industry, encompasses slow production at the company level and slow consumption at the consumer level. Slow consumption is fostering an increased awareness among consumers of how they are supporting an unsustainable and socially irresponsible business model by purchasing regularly and in large quantities from $\mathrm{FF}$ companies, and necessitates a shift in the consumer mindset from the quantity to the quality of purchases [8, 21-22]. For a paradigm shift toward slow fashion to take hold on a large scale, "a transformation of the institutions and sacrifices from both consumers and producers" will be required [7]. Although FF companies are investing in sustainability initiatives, they are unlikely to overhaul their business models anytime soon. Therefore, the paradigm shift toward slow production will build in other sectors of the retail industry, such as the luxury sector which is already experiencing growing momentum toward sustainable development, and will rely on increased consumer awareness to fuel the move toward slow consumption at the consumerlevel [19-20].

Research suggests that "consumers who are able to acquire a level of symbolic capital that distinguishes them from their peers...[have a] growing role in signaling to producers as well as other consumers the kind of field-level changes that are desirable and possible" [39]. Fashion leaders, through their symbolic capital, fuel fashion diffusion and are also attuned to general information related to the fashion industry $[10,20]$. Spurring fashion leaders toward environmentally conscious consumption is proposed to "encourage its widespread adoption among general consumers" [10]. Although they are considered to be the most informed consumer demographic on fashion-related information (e.g., seasonal trends), it is proposed that fashion leaders actually have limited knowledge of the environmental impact of the clothing industry and the sustainability initiatives (or lack thereof) of apparel companies [13, 36]. It is also proposed that fashion leaders may report an interest in obtaining more information on these topics and report that such information would affect their purchase decisions [31, 41]. The purpose of this exploratory study is to probe more deeply into the relationship between fashion leaders' sustainability awareness and purchase intentions by gauging the following: a) fashion leaders' current and desired levels of knowledge related to sustainable apparel production and consumption, b) whether sustainability awareness influences fashion leaders' orientation toward slow consumption and motivation to avoid purchasing fast-fashion, and c) how fashion leaders' orientation to slow consumption influences their drivers of fast fashion avoidance.

\section{Relevant Literature and Hypothesis Development}

\subsection{Fashion Leaders and Sustainability}

Fashion leaders are defined as consumers who "have more interest in fashion, spend more money on clothes, search for more fashion-related information, shop more often, and try more new fashion items than others" [10]. The fashion media and the celebrities, with whom they identify or idealize, also heavily influence fashion leaders' purchase intentions [31]. Fashion leaders, in turn, influence others (i.e., fashion followers) to adopt new fashion trends and consumption behaviors [41]. For example, these consumers often lead the way in mainstreaming new forms of consumption such as mobile app shopping.

Scaraboto and Fischer explored the role of the consumer in initiating marketplace change, finding that consumers with high levels of symbolic and cultural capital (i.e., knowledge, education) can themselves legitimize products and practices in the marketplace instead of merely interpreting marketers' efforts to create legitimacy, such as companies in the FF industry marketing themselves as sustainable [39]. The authors suggest that consumers, such as fashion leaders, in concert with more powerful institutional actors (e.g., celebrities, NGOs), can mobilize and fuel diffusion of change agendas within organizational fields [39]. Ertekin and Atik echoed this finding, proposing that the shift to a more sustainable fashion industry that is both profitable and poised 
for social and environmental longevity will require the formation of a collective sustainability-oriented identity within the fashion system [7]. The fashion system is "one of the modes responsible for the creation and movement of cultural meaning," and includes organizations and their supply chains, the media, fashion associations, celebrities, influencers, design and fashion schools and consumers with varying levels of fashion involvement (e.g., fashion leaders, late adopters, fashion followers) [7]. The sample for the present research study consists of individuals who are selfdescribed fashion leaders who exert influence at the micro level (e.g., reference groups) through their consumption practices. In addition, many study participants are future industry professionals who, in the coming years, will help shape the sustainable agenda at the macro level through their careers in the fashion sector.

Research suggests that fashion leaders can be instrumental, along with other institutional actors, in the paradigm shift toward a more sustainable fashion system [7, 39]. At the same time, research suggests that young female fashion leaders (i.e., 18-24) are the most active FF shoppers and demonstrate a propensity toward overconsumption [20, 22, 30-31]. These consumers are tempted to regularly purchase large quantities of low cost, on-trend merchandise from FF retailers, especially when there is a perceived lack of comparable alternatives in the market [23]. Two major themes are evident in the literature that provide insight into the relationship between fashion leaders and sustainability, the existence of a pro-environmental attitude-behavior gap and a general lack of knowledge about the environmental impact of apparel production and consumption.

\subsubsection{The Pro-environmental Attitude-Behavior Gap}

Despite evidence of increasing environmental and social concern in recent years, there appears to be a disconnect between consumers' attitudes toward sustainable consumption and their actual consumption behaviors. This is referred to as the pro-environmental attitude-behavior gap [7, 30]. Fashion leaders do have positive attitudes toward environmentalism and are concerned about their environmental and social impact $[10,38]$. They engage in pro-environmental behaviors such as recycling, using public transportation, and consuming organic food but seem to disassociate sustainability from their fashion purchase and disposal habits $[6,13,20]$. Because being fashionable is an important facet of fashion leaders' identity construction, their desire to acquire new fashions is often in direct opposition with their desire to limit consumption $[19,30,34]$. In terms of FF apparel, poor quality and short product life-spans are often justified by affordability and fashion-forwardness [23]. Research exploring the disposal of apparel has found that fashion leaders may acknowledge the "throwaway culture" that FF perpetuates while simultaneously expressing relatively low levels of guilt related to the disposal of large quantities of low cost garments. However, they reference higher levels of guilt when disposing of expensive purchases $[20,31]$. Thus, highly involved fashion consumers seem to be compartmentalizing their sustainability concerns and consumption behaviors [18, 23, 32]. If they "recognize the demands that fast fashion [and overconsumption] makes on the environment, they seem to block it from their consciousness" [20].

\subsubsection{Lack of Consumer Awareness}

It is clear in the literature on highly involved fashion consumers that there is a general lack of awareness "about the impact of unsustainable production and consumption created by fast fashion products" [34]. This can be explained by several factors. First, although the recent increase in media coverage related to sustainability challenges (e.g., climate change, resource depletion) has contributed to increased consumer awareness about these macro-level issues, messages that could limit consumption, the major driver of a society's economic growth, have been severely limited. Further, the "economic importance of the fast fashion industry globally has protected it somewhat from criticism of its inherent obsolescence and waste, thus, slowing an industry-wide movement toward ethical practice and legitimising the role of unethical fast fashion in the marketplace" [30].

The FF industry has taken what researchers describe as a reactive approach to sustainability $[5,34]$. FF companies have invested in and widely publicized their sustainability commitments in order to satisfy the concerns of environmentally-conscious consumers while fostering overconsumption and making no effort to alter their business models. These messages position sustainability as a company-facing issue (e.g., ethical labor practices, efforts toward more sustainable supply chains, etc.) and largely avoid transferring responsibility to the consumer [15]. Therefore, consumers are not prompted to consider "that purchasing is always a moral - and not simply economicact... [and that] the consumer has a specific social responsibility, which goes hand-in-hand with the social responsibility of the enterprise [25]. In addition, FF brands' sustainable marketing strategies have somewhat overshadowed the proactive approach of sustainable fashion brands that aim to lead the whole industry toward more sustainable manufacturing, purchasing, use, and disposal of apparel and textiles [15, 20, 34]. Moreover, the sustainable fashion sector is growing but it is "still a niche market rather than a mass-market reality," which limits the reach of its platform to promote awareness of sustainability issues [7]. However, research suggests that consumers are becoming more aware of the extent to which they are socialized to consume and, despite the existence of the pro-environmental attitude-behavior gap, demonstrate an ability to critically examine the origins of their consumption motivations and how their fashion consumption practices align with their values $[6,13,30,31]$.

A second factor that impacts consumer awareness is that there is no governing body for sustainability in the apparel industry as there are in other sectors such as the U.S. food (e.g., USDA) and cosmetics (e.g., FDA) sectors [8]. The 
apparel sector is a global industry, which makes standardization even more of an obstacle and allows companies to tailor their sustainability initiatives to suit their own business strategies. The third factor is that in the absence of clear corporate communication on these issues, "the highly fragmented and complex nature of the apparel supply chain makes it extremely difficult for average consumers to understand the cause and effect of fast fashion brands' businesses" [34]. It is clear that increased consumer awareness about unsustainable FF driving unsustainable consumption is needed as knowledge is an antecedent to behavioral intention. Morgan and Birtwistle found that educating fashion leaders about the quantity of textile waste that ends up in landfills, the resulting environmental impact, and alternative clothing disposal practices (e.g., recycling, donation), positively impacted their behavioral intention toward those practices [31]. Gam suggested that, because fashion leaders actively seek out fashion-related information, increasing the amount of available content about environmentally friendly clothing (EFC) will expose them to this information and positively affect their motivation to purchase EFC and the likelihood that they will consider sustainability criteria in their broader apparel purchases [10]. McNeill and Moore found that highly involved fashion consumers believe that "sustainability and ethical production information [should] be more explicit" [30]. Sadachar et al. investigated how environmental apparel knowledge and fashion leaders' materialistic values influence the attitudebehavior gap [38]. The researchers found that environmental apparel knowledge positively influenced environmental concern and that environmental concern positively influenced environmentally responsible apparel consumption, confirming that "knowledge affects attitude, which, in turn, drives behavior" [38]. The finding that "environmental apparel knowledge did not have any association with materialism...[indicates] that greater knowledge of environmental apparel issues is unlikely to effectively decrease people's desire for possessions" [38].

These studies' findings are all noteworthy because the message of slow consumption is not "don't buy," but instead that consumers should reduce the speed and quantity of consumption and purchase high quality products that are sustainably produced and designed for longevity. Furthermore, evidence supports the value of knowledge as an impetus for behavioral change. If fashion leaders gain more knowledge about how, both organizations (e.g., FF) and consumers (e.g., overconsumption, apparel waste) perpetuate the negative environmental and social effects of FF, they may be motivated to adopt more sustainable consumption practices and limit or avoid FF. To that end, this exploratory study investigates fashion leaders' level of sustainability knowledge and how this knowledge influences their orientation to slow consumption and fast fashion avoidance drivers.

\subsection{Theoretical Framework}

Two theoretical frameworks were adapted and employed to guide the development of the present study, Jung and Jin [21-22] and Kim et al. [23]. To the authors' knowledge, they are the only two frameworks in the literature that have explicated and validated the dimensions of slow consumption and fast fashion avoidance, respectively.

\subsubsection{Orientation to Slow Consumption}

Slow fashion "encompasses the whole range of 'sustainable,' 'eco,' 'green,' and 'ethical' fashion movements... [and means] not only slowing down the consumption and production processes, but also protecting the well-being of the workers, communities, and the environment" [7]. This philosophy asks that consumers question their established practices and worldviews, including the economic models that underpin fashion production and consumption [7, 30]. Jung and Jin [21-22] conceptualized, tested, and validated dimensions of slow fashion (i.e., social equity, localism, authenticity), which were adapted to form the "orientation to slow consumption" dimension in the present study. The first dimension, social equity, implies fair trade throughout the production system, meaning respect and fair compensation for producers along with good working conditions and no excessive workloads. Jung and Jin [21] suggest that social equity adds value to consumer purchases in the form of increased quality, longer lifespans, and knowledge that purchases were ethically produced. The second dimension, authenticity, concerns the value added to products through highly skilled and craftbased production methods, the time spent on each piece, and the story behind a product's journey to the end consumer [2122]. Authenticity is contrary to the perspective of clothing as disposable, proposing that consumers who purchase high quality apparel form more emotional connections with their apparel. These emotional connections prompt consumers to keep their apparel longer and take better care of their garments, two behaviors that characterize slow consumption [41]. The third dimension, localism, denotes consumers' preference for domestic over global apparel brands, including businesses that source local resources for apparel production, as the environmental cost of localism is less than that of global production [21-22]. Based on Jung and Jin's [21-22] model and the extant research [10, 30-31, 38], which links sustainability awareness, attitudes, and behavioral intentions, the following hypothesis was proposed:

H1. Sustainability awareness positively influences orientation to slow consumption.

\subsubsection{Fast-Fashion Avoidance}

Kim et al. proposed a model of fast fashion avoidance, or the "attitudes and behaviors against fast fashion and its consumption" [23]. The authors conceptualized and tested a model comprising multi-dimensional drivers of FF avoidance, including the potential moderating effect that may arise from a lack of alternatives in the market. The drivers were adapted to form the "fast fashion avoidance" dimension in the present study: poor performance, deindividuation, overly trendy style, big store discomfort, inauthenticity, and irresponsibility [23]. Poor performance encompasses 
consumers' negative beliefs about the functional attributes of $\mathrm{FF}$, while deindividuation is the perception that FF hinders the creation of a unique personal style. The variable, overly trendy styles, relates to the belief that FF styles go in and out of fashion too rapidly to be practical for long-term use. Inauthenticity suggests that consumers are aware that FF merchandise assortments copy on-trend styles from high fashion. Unsurprisingly, Kim et al. found that inauthenticity negatively affected FF avoidance, suggesting that consumers are motivated to purchase the on-trend styles that are copied from high fashion [23]. While expressing concern for FF's lack of uniqueness (i.e., deindividuation), participants were still eager to purchase low-price interpretations of designer trends [23]. Big store discomfort includes negative beliefs about store size, merchandise organization, and wait times for dressing rooms and at the point of sale. Irresponsibility is the belief that FF fosters overconsumption, exploits labor in developing countries, and causes environmental harm and resource depletion. Kim et al. found that perceptions of FF's ethical and environmental impact did not influence consumers' FF purchase intentions [23]. However, study participants' level of sustainability awareness was not explored in conjunction with respondents' beliefs about FF as it is in the present study. Based on Kim et al.'s [23] model and the extant research [10, 30-31, 38], which links sustainability awareness, attitudes, and behavioral intentions, the following hypothesis was proposed:

H2. Sustainability awareness positively influences the drivers of fast fashion avoidance.

\subsubsection{Slow Fashion Orientation and Drivers of Fast Fashion Avoidance}

The limited research exploring fashion leaders, slow consumption orientation, and drivers of FF avoidance has highlighted the complexities associated with these individuals' desire to follow trends and consume sustainably [7, 19-20, 38-39]. Jung and Jin found that, just as fashion leaders' patron multiple brands in pursuit of style trends, they are also not "exclusively engaging in either slow or fast fashion" and may even consider fast and slow fashion as having a complementary relationship since they often fill different consumer needs [22]. Watson and Yan explicated key differences (e.g., resources, motivations, attitudes, values) between slow and fast fashion consumers, yet also identified some overlap in the two groups such as an agreement about the wasteful nature of disposable clothing [41]. The authors concluded that "fashion is a dynamic process which begins and ends at an individual level depending on lifestyles and social trends...[and suggested] that environmental or societal factors may be shifting the popularity of these constructs" [41]. The focus on sustainability is continuing to increase and it is now apparent that addressing the breadth of challenges facing the sector will require a joint commitment by the industry and its consumers [7]. Only then can we transition to a more sustainable apparel system [28, 37].

It is reasonable to assume that galvanizing the slow fashion movement at the consumer level (i.e., slow consumption) may be a challenge among fashion leaders, who exhibit opposing desires to practice slow consumption and support their identity construction through regular clothing consumption (e.g., FF). Therefore, research investigating how consumers that are more prone toward overconsumption (e.g., fashion leaders) can be prompted to adopt more sustainable consumption behaviors will have meaningful practical implications for slow fashion marketers. To the authors' knowledge, no study has been conducted that explores fashion leaders' sustainability knowledge concurrent with their desires to follow trends and practice sustainable consumption. Thus, examining this relationship is a reasonable starting place to expand the theoretical understanding of these constructs [19, 30, 34]. Assuming that fashion leaders' favorable orientation to slow consumption influences their attitudes and behavioral intentions toward $\mathrm{FF}$, the following hypothesis was proposed:

H3. Orientation to slow consumption positively influences the drivers of fast fashion avoidance.

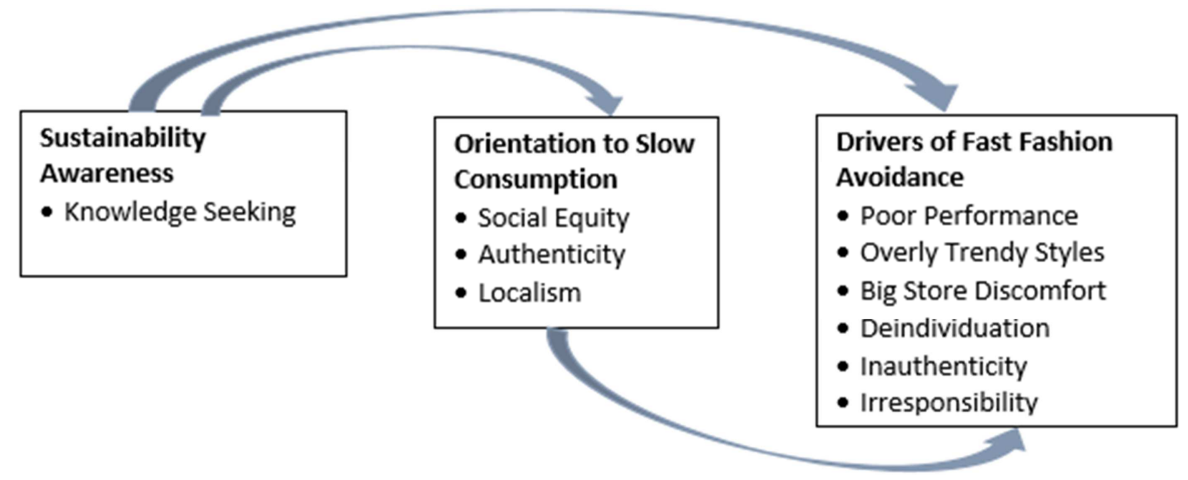

Figure 1. Conceptual Model.

\section{Research Method}

\subsection{Sampling and Data Collection}

The purpose of this exploratory study is to explore how fashion leaders' level of sustainability awareness and orientation to slow consumption influence their FF avoidance. Data were collected from a convenience sample of retailing students at two U.S. universities, yielding 520 responses. The researchers assumed that students enrolled in 
collegiate retailing programs would have a personal interest in fashion and would report moderate to high levels of fashion leadership. To ensure that the sample only consisted of self-described fashion leaders, a composite score of the three fashion leadership items (i.e., "I consider myself to be trend-conscious," "I demonstrate knowledge and give information about fashion to others," "being a fashion leader is important to me") was calculated and only the responses with scores higher than four for the composite variable were selected for further analyses. As a result, 405 responses were selected. The sample was 85 percent female $(n=344)$ and 15 percent male $(n=61)$. Ninety-nine percent of the sample ranged from 18-25 years old. The majority of the sample was Caucasian (82\%) followed by African-American (8.9\%). Sixty-three percent $(n=255)$ of respondents reported that they shop for apparel more than three times per month. Eighty-five percent $(n=361)$ of respondents spend less than $\$ 100$ per shopping trip. Respondents also confirmed their diverse apparel shopping preferences, indicating that they shop at FF companies $(73.8 \%)$ in addition to high-end apparel brands (73.6\%), second-hand stores/websites selling on-trend and luxury merchandise (73.6\%), and thrift stores $(47.7 \%)$.

\subsection{Measures}

The measurement items used in the study were selected based on a review of the extant literature and a focus group interview. Even though most measurement items were drawn from the literature, in some cases, slight modifications were needed to tailor the items to the research setting. The survey instrument, an online questionnaire, consisted of eight demographic questions and 103 closed-ended interrogative questions on a 7-point Likert scale (i.e., 1= strongly disagree, $7=$ strongly agree). The researchers developed a conceptual model (see Figure 1), based on existing literature [22-23], that guided testing of the relationships proposed in the hypotheses.

\subsection{Conceptual Model Development}

The "sustainability awareness" dimension of the proposed model includes one exogenous variable (i.e., knowledge seeking). Scale items for the variable measured fashion leaders' current and desired levels of knowledge related to sustainable apparel production and consumption [30-31, 34]. The "orientation to slow consumption" dimension included three endogenous variables. Scale items for the variables measured drivers of fashion leaders' orientation to slow consumption, including mindfulness of fair labor and fair trade (i.e., social equity), appreciation of craftsmanship (i.e., authenticity), and preference for domestic brands that support local economies (i.e., localism) [21-22]. The "drivers of fastfashion avoidance" dimension included six endogenous variables (i.e., poor performance, overly trendy style, big store discomfort, deindividuation, inauthenticity, irresponsibility) identified as motivational drivers of fastfashion avoidance [23].

\section{Results}

\subsection{Preliminary Analysis and Testing of Conceptual Model}

Structural equation modeling (SEM) with AMOS graphics version 19.0 was used to analyze the data and parameters were estimated using maximum likelihood method. Reliability was examined through confirmatory factor analysis (CFA) and the calculation of Cronbach's alpha coefficients (above .70). Convergent validity was assessed by examining the analysis of statistical significance of the parameter estimates between latent constructs and their indicators. All path weights were significant $(\mathrm{p}<0.001)$ and the composite reliabilities of all constructs except "inauthenticity" were greater than the minimum criteria of 0.70 , indicating adequate convergent validity (see Table 1). In the case of inauthenticity, even though the composite reliability was slightly low (0.66), the factor loadings of two items were significantly high $(\gamma=0.69, \gamma=0.71)$. Discriminant validity examines the discriminance of items on latent constructs that they are not intended to measure [1]. Average Variance Extracted (AVE) was used to test discriminant validity. AVE values ranged from 0.49 to 0.79 , supporting convergent validity. Discriminant validity was then assessed by comparing the average variance extracted (AVE) of each construct and the shared variance (i.e., squared correlation coefficient) between all possible pairs of constructs [9]. The average variance extracted (AVE) should be larger than the shared variance (i.e., squared correlation coefficients) between all possible pairs of constructs. All AVE values were significantly larger than shared variance. None of the squared correlations exceed the AVE values for any of the constructs, indicating discriminant validity (See Table 2). In addition, the measurement model showed a good model fit: $\chi^{2}(304)=653.52 ; \chi^{2} / \mathrm{df}$ ratio $=2.15 ; \mathrm{CFI}=0.94$; RMSEA $=0.053)$. The results of CFA produced chi-squaredegrees of freedom ratio well below the criterion of Marsh and Hocevar [27].

Table 1. Results of Measurement Model Analysis.

\begin{tabular}{|c|c|c|}
\hline Construct/scale items (Composite Reliability, AVE) & Std. Est. & t-value \\
\hline \multicolumn{3}{|l|}{ Knowledge Seeking $(\mathrm{CR}=0.83, \mathrm{AVE}=0.71)$} \\
\hline I would be interested to hear more about the environmental sustainability initiatives of apparel companies in the news & 0.82 & $18.15 * * *$ \\
\hline $\begin{array}{l}\text { Having knowledge of whether apparel companies have environmental sustainability initiatives in place affects my } \\
\text { purchase decisions }\end{array}$ & 0.87 & $19.66 * * *$ \\
\hline \multicolumn{3}{|l|}{ Social Equity $(\mathrm{CR}=0.85, \mathrm{AVE}=0.66)$} \\
\hline I am concerned about the working conditions of employees throughout the apparel supply chain when I buy clothes & 0.80 & $18.15 * * *$ \\
\hline Fair compensation for employees throughout the apparel supply chain is important to me when I buy clothes & 0.85 & $19.982 * * *$ \\
\hline
\end{tabular}




\begin{tabular}{|c|c|c|}
\hline Construct/scale items (Composite Reliability, AVE) & Std. Est. & t-value \\
\hline \multicolumn{3}{|l|}{ Authenticity $(\mathrm{CR}=0.76, \mathrm{AVE}=0.52)$} \\
\hline If given the choice, I would purchase handcrafted clothing instead of mass-produced clothing & 0.63 & $12.682 * * *$ \\
\hline Craftsmanship is important to me when buying apparel & 0.86 & $17.882 * * *$ \\
\hline \multicolumn{3}{|l|}{ Localism $(\mathrm{CR}=0.76, \mathrm{AVE}=0.52)$} \\
\hline Consumers need to support U.S. apparel brands & 0.67 & $13.36 * * *$ \\
\hline I prefer buying clothing made in the U.S. to clothes manufactured overseas & 0.69 & $13.85 * * *$ \\
\hline $\begin{array}{l}\text { I believe clothing made from locally produced materials is more valuable than clothing made from materials sourced } \\
\text { from overseas }\end{array}$ & 0.80 & $16.52 * * *$ \\
\hline \multicolumn{3}{|l|}{ Poor Performance $(\mathrm{CR}=0.87, \mathrm{AVE}=0.57)$} \\
\hline Fast fashion stitching is not strong enough & 0.62 & $13.14 * * *$ \\
\hline Fast fashion product quality is not good enough & 0.74 & $16.42 * * *$ \\
\hline Fast fashion clothing's form often changes after washing and repeated use & 0.73 & $16.14 * * *$ \\
\hline Cheap material is used in fast fashion clothing & 0.83 & $19.57 * * *$ \\
\hline Fast fashion clothing is low priced and not durable & 0.82 & $19.27 * * *$ \\
\hline \multicolumn{3}{|l|}{ Overly Trendy Style $(\mathrm{CR}=0.73, \mathrm{AVE}=0.57)$} \\
\hline Fast fashion clothing styles are too trendy to use for a long time & 0.73 & $14.76^{* * *}$ \\
\hline Fast fashion clothing styles are too sensitive to changing trends & 0.78 & $15.77 * * *$ \\
\hline \multicolumn{3}{|l|}{ Big Store Discomfort $(\mathrm{CR}=0.77, \mathrm{AVE}=0.52)$} \\
\hline Fast fashion clothing stores are too big to look around & 0.70 & $14.34 * * *$ \\
\hline Fast fashion clothing displays are not well organized & 0.75 & $15.50 * * *$ \\
\hline In fast fashion clothing stores, the wait time for a cashier is too long & 0.71 & $14.56 * * *$ \\
\hline \multicolumn{3}{|l|}{ Deindividuation $(\mathrm{CR}=0.88, \mathrm{AVE}=0.79)$} \\
\hline Wearing fast fashion makes it hard to express my personality & 0.92 & $20.28 * * *$ \\
\hline Wearing fast fashion makes it hard to create my own style & 0.86 & $18.69 * * *$ \\
\hline \multicolumn{3}{|l|}{ Inauthenticity $(\mathrm{CR}=0.66, \mathrm{AVE}=0.49)$} \\
\hline Fast fashion styles have too much mass appeal & 0.69 & $13.35 * * *$ \\
\hline Fast fashion styles look like copies & 0.71 & $13.74 * * *$ \\
\hline \multicolumn{3}{|l|}{ Irresponsibility $(\mathrm{CR}=0.88, \mathrm{AVE}=0.71)$} \\
\hline The fast fashion industry pollutes the environment & 0.91 & $22.70^{* * *}$ \\
\hline The fast fashion industry is one of the top polluting industries in the world & 0.85 & $20.33 * * *$ \\
\hline Fast fashion exploits labor in less developed countries & 0.76 & $17.51 * * *$ \\
\hline
\end{tabular}

Table 2. Discriminant Validity: Comparison of AVE and Squared Correlations.

\begin{tabular}{lllllllllll}
\hline & $\mathbf{1}$ & $\mathbf{2}$ & $\mathbf{3}$ & $\mathbf{4}$ & $\mathbf{5}$ & $\mathbf{6}$ & $\mathbf{7}$ & $\mathbf{8}$ & $\mathbf{9}$ & $\mathbf{1 0}$ \\
\hline Knowledge Seeking & 0.71 & & & & & & & & & \\
Social Equity & 0.44 & 0.66 & & & & & & & \\
Authenticity & 0.23 & 0.20 & 0.52 & & & & & & \\
Localism & 0.23 & 0.17 & 0.20 & 0.52 & & & & & \\
Poor Performance & 0.06 & 0.06 & 0.08 & 0.10 & 0.56 & & & & \\
Overly Trendy Style & 0.03 & 0.08 & 0.10 & 0.11 & 0.31 & 0.57 & & & \\
Big Store Discomfort & 0.02 & 0.06 & 0.03 & 0.07 & 0.24 & 0.36 & 0.52 & & \\
Deindividuation & 0.01 & 0.06 & 0.06 & 0.04 & 0.05 & 0.30 & 0.13 & 0.79 & \\
Inauthenticity & 0.09 & 0.09 & 0.17 & 0.16 & 0.29 & 0.32 & 0.28 & 0.29 & 0.49 & \\
Irresponsibility & 0.34 & 0.22 & 0.15 & 0.18 & 0.28 & 0.10 & 0.10 & 0.01 & 0.27 & 0.71 \\
\hline
\end{tabular}

\subsection{Path Analyses for Testing Hypotheses}

To test the hypotheses, a structural model was established. Goodness-of-fit statistics for the structural model were also acceptable: $\chi 2(320)=754.24 ; \chi 2$ /df ratio $=2.36 ; \mathrm{CFI}=0.92$; RMSEA $=0.058$ (see Table 3 ). The results show that sustainability awareness positively influences consumer orientation to slow consumption (social equity $\gamma=0.70, p<$ 0.001; authenticity, $\gamma=0.95, p<0.001$; localism, $\gamma=0.53, p$ $<.001)$. However, sustainability awareness was negatively related to FF avoidance $(p<.01)$. Thus, hypothesis H1 was supported and hypothesis H2 was not supported. Variables comprising the orientation to slow consumption dimension positively related to most FF avoidance variables. Social equity influenced overly trendy styles $(\beta=0.32, p<0.01)$, big store discomfort $(\beta=0.28, p<0.01)$, and deindividuation $(\beta=$ $0.37, p<0.001)$. Interestingly, social equity did not influence poor performance $(\beta=0.03, p=0.72)$, inauthenticity $(\beta=0.07$, $p=0.45)$, or irresponsibility of FF $(\beta=0.01, p=0.92)$. Authenticity and localism positively influenced all FF avoidance variables significantly $(p<0.001)$ except the path of localism and irresponsibility $(\beta=0.1, p=0.12)$. Therefore, hypothesis H3 was partially supported.

Table 3. Results of Path Analysis.

\begin{tabular}{|c|c|c|c|c|c|}
\hline Path Analysis & Estimate & Std. Error & t-value & \multicolumn{2}{|c|}{ Structural Equation Fit $\left(\mathbf{R}^{2}\right)$} \\
\hline Knowledge Seeking $\rightarrow$ Social Equity & 0.70 & 0.06 & $11.42 * * *$ & \multirow{2}{*}{ Social Equity } & \multirow{2}{*}{0.49} \\
\hline Knowledge Seeking $\rightarrow$ Authenticity & 0.95 & 0.06 & $9.46^{* * *}$ & & \\
\hline Knowledge Seeking $\rightarrow$ Localism & 0.53 & 0.04 & $7.75 * * *$ & Authenticity & 0.89 \\
\hline
\end{tabular}




\begin{tabular}{|c|c|c|c|c|c|}
\hline Path Analysis & Estimate & Std. Error & t-value & \multicolumn{2}{|c|}{ Structural Equation Fit $\left(\mathbf{R}^{2}\right)$} \\
\hline & $-1 . / 1$ & 0.33 & $-3.13 * 6$ & \multirow{3}{*}{ Localism } & \multirow{3}{*}{0.28} \\
\hline Knowledge Seeking $\rightarrow$ Overly Trendy Style & -2.33 & 0.48 & $-3.71 * * *$ & & \\
\hline Knowledge Seeking $\rightarrow$ Big Store Discomfort & -2.06 & 0.46 & $-3.67 * * *$ & & \\
\hline Knowledge Seeking $\rightarrow$ Deindividuation & -1.60 & 0.47 & $-3.81 * * *$ & \multirow{2}{*}{ Poor Performance } & \multirow{2}{*}{0.51} \\
\hline Knowledge Seeking $\rightarrow$ Inauthenticity & -1.93 & 0.38 & $-3.17 * *$ & & \\
\hline Knowledge Seeking $\rightarrow$ Irresponsibility & -0.47 & 0.33 & -1.51 & \multirow{2}{*}{ Overly Trendy Style } & \multirow{2}{*}{0.64} \\
\hline Social Equity $\rightarrow$ Poor Performance & 0.03 & 0.05 & 0.37 & & \\
\hline Social Equity $\rightarrow$ Overly Trendy Style & 0.32 & 0.08 & $3.28 * *$ & \multirow{2}{*}{ Big Store Discomfort } & \multirow{2}{*}{0.49} \\
\hline Social Equity $\rightarrow$ Big Store Discomfort & 0.28 & 0.08 & $2.87 * *$ & & \\
\hline Social Equity $\rightarrow$ Deindividuation & 0.37 & 0.10 & $4.11 * * *$ & \multirow{2}{*}{ Deindividuation } & \multirow{2}{*}{0.31} \\
\hline Social Equity $\rightarrow$ Inauthenticity & 0.07 & 0.06 & 0.75 & & \\
\hline Social Equity $\rightarrow$ Irresponsibility & 0.01 & 0.08 & 0.10 & \multirow{2}{*}{ Inauthenticity } & \multirow{2}{*}{0.65} \\
\hline Authenticity $\rightarrow$ Poor Performance & 1.97 & 0.56 & $3.50 * * *$ & & \\
\hline Authenticity $\rightarrow$ Overly Trendy Style & 2.22 & 0.79 & $3.47 * * *$ & \multirow{16}{*}{ Irresponsibility } & \multirow{16}{*}{0.53} \\
\hline Authenticity $\rightarrow$ Big Store Discomfort & 1.96 & 0.77 & $3.43 * * *$ & & \\
\hline Authenticity $\rightarrow$ Deindividuation & 1.40 & 0.76 & $3.28^{* *}$ & & \\
\hline Authenticity $\rightarrow$ Inauthenticity & 2.18 & 0.63 & $3.48 * * *$ & & \\
\hline Authenticity $\rightarrow$ Irresponsibility & 1.11 & 0.55 & $3.47^{* * *}$ & & \\
\hline Localism $\rightarrow$ Poor Performance & 0.20 & 0.07 & $2.69 * *$ & & \\
\hline Localism $\rightarrow$ Overly Trendy Style & 0.24 & 0.11 & $2.97 * *$ & & \\
\hline Localism $\rightarrow$ Big Store Discomfort & 0.30 & 0.10 & $3.58 * * *$ & & \\
\hline Localism $\rightarrow$ Deindividuation & 0.21 & 0.13 & $2.78 * *$ & & \\
\hline Localism $\rightarrow$ Inauthenticity & 0.27 & 0.08 & $3.20 * *$ & & \\
\hline Localism $\rightarrow$ Irresponsibility & 0.10 & 0.11 & 1.57 & & \\
\hline Measurement Model Fit Statistics: & & \multirow{2}{*}{\multicolumn{2}{|c|}{$\begin{array}{l}\text { Structural Model Fit Statistics: } \\
\chi^{2}(320)=754.24\end{array}$}} & & \\
\hline$\chi^{2}(304)=653.52$ & & & & & \\
\hline$\chi^{2} / d f=2.15$ & & \multicolumn{2}{|c|}{$\chi^{2} / \mathrm{df}$ ratio $=2.36$} & & \\
\hline $\mathrm{CFI}=0.94$ & & \multicolumn{2}{|l|}{$\mathrm{CFI}=0.92$} & & \\
\hline RMSEA $=0.053$ & & \multicolumn{2}{|c|}{ RMSEA $=0.058$} & & \\
\hline
\end{tabular}

\subsection{Regression Analysis}

After testing the relationships among sustainability awareness, orientation to slow consumption, and the drivers of fast fashion avoidance, the researchers decided to examine the predictive power of these variables for a shopping preference toward fast fashion companies. The dependent variable used for the regression analysis was "I shop at fast fashion companies." As illustrated in Table 4, Knowledge Seeking positively influenced shopping at fast fashion companies $(\beta=0.11, \mathrm{t}=1.74, p<.01)$. This result is consistent with the structural model results, that knowledge seeking was negatively related to drivers of fast fashion avoidance $(p<.01)$. It also confirmed that respondents' knowledge related to sustainability, especially for the environment, was not linked to the production or operation of fast fashion companies. Irresponsibility also positively influenced shopping at fast fashion companies $(\beta=0.2, \mathrm{t}=$ $3.12, p<.001)$. Even if consumers know that the FF industry pollutes the environment and fuels overconsumption, these factors do not discourage their shopping preference towards fast fashion companies.

However, social equity $(\beta=-0.15, \mathrm{t}=-2.41, p<.005)$ and deindividuation $(\beta=-0.18, \mathrm{t}=-3.15, p<.001)$ negatively influenced shopping at fast fashion companies. These results suggest that respondents who have more concern about working conditions, employee compensation, and fair trade are less likely to purchase fast fashion. In addition, consumers who are seeking personalized styles do not like shopping at fast fashion companies.

Table 4. Results of Regression Analysis.

\begin{tabular}{llllll}
\hline & \multicolumn{2}{l}{ Unstandardized Coefficients } & Standardized Coefficients & t & Sig. \\
\cline { 2 - 5 } & B & Std. Error & Beta & & 12.35 \\
(Constant) & 5.03 & 0.41 & 0.11 & 1.74 & 0.00 \\
Knowledge Seeking & 0.10 & 0.06 & -0.15 & -2.41 & 0.08 \\
Social Equity & -0.14 & 0.06 & -0.05 & -0.90 & 0.02 \\
Authenticity & -0.06 & 0.06 & 0.04 & 0.75 & 0.37 \\
Localism & 0.05 & 0.06 & -0.05 & -0.90 & 0.46 \\
Poor Performance & -0.07 & 0.07 & -0.09 & -1.41 & 0.37 \\
Overly Trendy Style & -0.09 & 0.07 & 0.04 & 0.75 & 0.16 \\
Big Store Discomfort & 0.05 & 0.06 & -0.18 & -3.15 & 0.45 \\
Deindividuation & -0.15 & 0.05 & 0.07 & 1.09 & 0.00 \\
Inauthenticity & 0.08 & 0.07 & 0.20 & 3.12 & 0.28 \\
Irresponsibility & 0.20 & 0.07 & & & 0.00 \\
\hline
\end{tabular}




\section{Discussion and Implications}

This research adopts the perspective of Peattie [35] who proposed that there is no such thing as a truly 'green consumer' and McDonald et al. who stated that, despite engaging in some green consumption practices, all consumers demonstrate "at least some element of 'grey' consumption in product sectors where green alternatives clearly exist" [29]. Especially for highly trend conscious consumers, the desire to acquire new fashions is often in direct opposition with the desire to limit consumption [19, 30], leading them to compartmentalize their sustainability concerns and fashion purchase/disposal habits [20]. This phenomenon is referred to as the pro-environmental attitudebehavior gap [7, 30]. This research further explores the complex relationship between fashion leaders' motivations toward slow versus fast fashion, and proposing that all consumers have the potential to adopt more sustainable consumption behaviors, offers suggestions for sustainable companies that aim to better understand and target these consumers.

This exploratory study addresses a gap in the literature by investigating whether fashion leaders' level of sustainability awareness and orientation to slow consumption influence their motivation to avoid purchasing fast-fashion (i.e., FF avoidance). The sample for the study was comprised of university students majoring in retail merchandising who selfidentified as fashion leaders, the most active FF shoppers that often demonstrate a propensity toward overconsumption [31]. Multiple findings merit discussion. With regard to the "knowledge seeking" variable, fashion leaders in the sample hinted at a general preference for retailers that they consider environmentally responsible by suggesting that having knowledge about companies' sustainability initiatives (or lack thereof) affects their purchase decisions. Further, these consumers' expressed an interest in hearing more about apparel companies' sustainability initiatives in the media. This finding is consistent with previous research highlighting the need for sustainable brands to increase marketing content geared toward educating consumers, not only about their sustainability agendas, but perhaps more importantly, with messages that educate them about the environmental and social issues that necessitate such agendas $[5,15,20]$. Participants' desire to learn more about companies' sustainability initiatives is encouraging as increased sustainability awareness can be an impetus for attitude and behavioral change [31,38]. In addition, because fashion leaders, through their symbolic and cultural capital, can play a role in diffusing change agendas in the field, such as the paradigm shift toward a more sustainable fashion system $[7,39]$.

A positive relationship existed between participants' awareness of sustainability issues and their motivation toward slow consumption (i.e., H1 supported), a finding that has been previously documented [21-22, 31, 38]. Participants' sustainability awareness was negatively related to the drivers of FF avoidance (i.e., H2 not supported). A few explanations exist for these seemingly contradictory findings.
It is plausible that fashion leaders in the sample are aware of FF retailers' (e.g., H\&M) widely-publicized sustainability initiatives, deeming these efforts socially responsible while not considering that the FF business model itself is unsustainable and fuels overconsumption, as these messages are downplayed in the media. Fashion leaders in the sample also indicated that their shopping preferences are diverse and include retailers with both FF and slow fashion strategies (e.g., luxury brands). The finding that sustainability awareness negatively influenced the motivational drivers of FF avoidance, coupled with the fact that survey respondents' acknowledged shopping at both fast and slow fashion retailers, suggests that FF retailers are succeeding in their efforts to position themselves as sustainable. It is concerning that fashion leaders, the most discerning consumer segment [10], cannot distinguish between companies that are taking a reactive approach to sustainability (e.g., $\mathrm{H} \& \mathrm{M}$ ) from those that have sustainability ingrained in their core values (e.g., Everlane). This suggests a need for sustainable companies to adopt marketing strategies that are more heavily focused on educating consumers about the underlying social and environmental impact of the clothing industry and overconsumption in order to further differentiate themselves from FF companies in the minds of consumers. The result that sustainability awareness does not directly influence the drivers of FF avoidance may also be attributed to the proenvironmental attitude-behavior gap $[7,30]$ and reinforce the claim that fashion leaders' environmental and social concerns may not extend to their consumption of FF [19-20, 34]. This outcome illustrates how fashion leaders must continually reconcile their desire for new fashions with their desire to limit consumption, and reinforces research suggesting that knowledge of sustainability challenges is unlikely to mitigate fashion leaders' desire for possessions [38]. However, research should continue to investigate the impact of sustainability awareness on fashion leaders' drivers of FF avoidance as sustainable fashion becomes increasingly mainstream and as sustainability continues to emerge as a megatrend across global industries [13].

The results indicate that there is support for orientation to slow consumption positively influencing many drivers of FF avoidance (i.e., H3 partially supported), although it is the non-significant relationships that may offer the most insight for sustainable fashion marketers. The first slow consumption dimension, social equity, did not influence the poor performance, inauthenticity, or irresponsibility driver of FF avoidance. This is not surprising because many consumers define sustainable fashion by its environmental, rather than social aspects [13]. These findings suggest that consumers have limited knowledge about how the FF business model often threatens the social equity (e.g., working conditions, fair labor) of actors in its supply chains. For example, the compressed fashion cycle means that runs inspired by seasonal trends (i.e., inauthenticity) are produced every 4-6 weeks, or less. The extreme pressure for factory workers to meet unrealistic production quotas affects product quality (i.e., poor performance) and often results in human rights 
violations (e.g., physical abuse by supervisors, unpaid overtime). These conditions are often detailed in NGO reports, such as Global Labour Justice's 2018 report on gender-based violence in Gap and H\&M's supply chains, but seldom receive visibility in the mainstream media [16]. An example of the irresponsibility of FF impacting social equity is evidenced by the production processes that pollute workers' natural environments throughout these supply chains. The results of the regression analysis (see Table 4) indicated that social equity did negatively influence "shopping at fast fashion," demonstrating that FF's violations of social equity are, in fact, a concern for these consumers. However, they still have limited knowledge about how specific social equity issues can manifest in each of the FF avoidance drivers. Additional research is needed to better understand how social equity can be leveraged to increase fashion leaders' behavioral intention to avoid FF.

The second slow consumption dimension, localism, positively influenced all of the FF avoidance drivers except irresponsibility. This finding suggests that marketers of sustainable fashion brands should more clearly communicate to consumers how adopting localized sourcing and production is a socially responsible strategy that supports their sustainability agendas (e.g., minimizing environmental impact of shipping, closer oversight of labor practices). In addition, sustainable brands should ensure that information detailing where each product's materials were sourced and where assembly took place is clearly displayed on their websites' product pages. Many larger companies (e.g., H\&M) that have begun to display these detailed product descriptions on their websites and/or garment tags have been criticized when watch groups have identified inaccuracies [2, 5]. Reporting "cradle to consumer" product information has proved a challenge for large FF companies due to their extensive and often-changing supplier networks. Sustainable companies have an advantage as their smaller scale allows them to maintain tighter holds on sourcing and production, whether localized or outsourced. As the trend toward transparency continues to spread, sustainable fashion retailers can leverage the localism dimension, sharing their commitment to working with local suppliers when possible and providing consumers with accurate and traceable product information. These messages also create an opportunity for sustainable brands to justify their price points through price transparency and motivate consumers to avoid FF by encouraging them to be more conscious of the ethics behind their apparel purchases and their choice of retailers [16, 33].

The third slow consumption dimension, authenticity, positively influenced all of the FF avoidance variables. This finding suggests that fashion leaders may be receptive to messaging by sustainable brands that the highlights product craftsmanship and personalized experiences that are lacking in FF. In addition, this finding highlights an opportunity for sustainable brands to leverage experiential content to tell stories about the artisans involved in their production processes, thereby cultivating deeper, more meaningful engagement between the brand, consumers, and the products they purchase. Fostering deep, long-lasting connections among consumers and the products they purchase is an important tenant of the slow fashion movement and a strategy that sustainable brands can employ to further differentiate themselves from FF brands who, despite their purported commitment to sustainability, still grow their businesses by promoting disposable fashion [14].

Regarding the irresponsibility driver of FF avoidance, respondents were very neutral on these questions $(m=4.7$, s.d. $=1.08)$. The regression analysis (see Table 4) further indicated that these fashion leaders either do not believe that $\mathrm{FF}$ is irresponsible or are compartmentalizing their sustainability concerns when it comes to FF (i.e., attitudebehavior gap). However, the path analysis (see Table 3) did identify one slow consumption dimension that positively and significantly influenced the irresponsibility driver of FF avoidance, authenticity. Fast Fashion retailers have become adept at promoting their sustainability commitments to position themselves as sustainable and avoiding messaging about the consumer-facing tenets of slow fashion (e.g., purchasing fewer, higher quality garments) that could challenge consumers to limit their consumption [7, 13, 20]. Nevertheless, research suggests that as slow fashion becomes more mainstream, branded content focused on authenticity, legitimacy and transparency will differentiate the truly sustainable corporations from those that are merely greenwashing [4, 11 14, 17].

Because authenticity is the only slow consumption dimension that positively influenced all drivers of FF avoidance, sustainable brands may consider prioritizing branded content geared toward authenticity as there is evidence that fashion leaders clearly distinguish between slow and fast fashion on this dimension. Messaging related to the localism and social equity dimensions is also needed and should be geared toward increasing consumer knowledge of the sustainability commitments encompassed by each construct to further leverage these dimensions to increase fashion leaders' behavioral intention to avoid FF. These strategies may be useful to sustainable apparel companies in promoting and positioning their fashion collections by highlighting the product and customer service criteria (e.g., high quality, timeless pieces, small-scale retail formats, personalized service, transparency). This would demonstrate to trend conscious consumers that sustainable fashion brands do offer many of the attributes desired in fast fashion (e.g., on-trend, reasonable prices) minus the negative attributes (e.g., poor product performance, inauthenticity) that are commonly cited by consumers, many of which also underpin the larger social and environmental issues within the FF industry. Clearer communication by NGOs, governments, educators, and sustainable apparel companies highlighting consumers' role in perpetuating the negative environmental effects of the apparel industry is also needed to position sustainability as both a company and consumer-facing responsibility [25]. Increased information dissemination on sustainability issues within the fashion system may limit consumers' (e.g., fashion leaders) ability to 
compartmentalize their pro-environmental concerns and consumption behaviors, thereby mitigating the attitudebehavior gap [19-20]. This is a necessary step toward turning the collective issue of overconsumption into an issue of personal responsibility [26], encouraging consumers not to support companies with unsustainable business models (e.g., fast fashion), and in transitioning consumer culture away from overconsumption.

\section{Conclusion and Future Directions}

This research explored the complex relationship between fashion leaders' motivations toward slow vs. fast fashion, providing insight into the pro-environmental attitudebehavior gap and how fashion leaders reconcile their sustainability knowledge with their consumption desires. Proposing that all consumers have the potential to adopt more sustainable consumption behaviors, this study investigated one consumer group (i.e. fashion leaders) and offered suggestions for how sustainable companies, as viable fast fashion alternatives, can better understand and target these consumers. There are a few limitations to this study. The conceptual model developed by the researchers was intentionally introductory, only considering direct effects, as this was the first attempt to explore how fashion leaders' sustainability awareness and orientation to slow consumption influence their motivation to avoid FF. Future research should include indirect effects and moderators and can also investigate FF avoidance itself, rather than only its drivers. The sample also consisted of retail merchandising students from two universities, one in the Southeastern and one in the Midwestern United States, and was predominantly female (i.e., $85 \%$ ) and Caucasian (i.e., $82 \%$ ). Therefore, the findings may not be generalizable to a larger population. Exploring a more diverse sample of fashion leaders may be meaningful (e.g., age, income, country) in order to identify additional factors that drive FF avoidance (e.g., financial resources, cultural values) [41]. Finally, future research on the drivers of FF avoidance can explore consumer awareness of FF's irresponsibility as it applies to both company (e.g., resource depletion) and consumer behaviors (i.e., overconsumption). Investigating "industry irresponsibility" and "consumer irresponsibility" as distinct drivers of FF avoidance will provide more insight into consumers' perceived responsibility in perpetuating the detrimental impact of FF. Concurrently examining fashion leaders' own irresponsibility, their sustainability awareness, and their orientation to slow consumption could be particularly useful to advancing our understanding of the pro-environmental attitude-behavior gap.

\section{References}

[1] Anderson, J. C. and Gerbing, D. W. (1988), "Structural equation modeling in practice: A review and recommended two-step approach," Psychological Bulletin, Vol. 103 No. 3, pp. 411-423.
[2] Bain, M. (2016), "Is H\&M misleading customers with all its talk of sustainability?", Quartz, available at: https://qz.com/662031/is-hm-misleading-customers-with-allits-talk-of-sustainability/ (accessed 20 April 2016).

[3] Bain, M. (2017), "Fast fashion's sad cycle of compulsive shopping, guilt, and regret has spread to Asia", Quartz, available at: https://qz.com/978679/fast-fashions-sad-cycle-ofcompulsive-shopping-guilt-and-regret-has-spread-to-asia/ (accessed 12 May 2017).

[4] Boston Consulting Group (2014), "How millennials are changing the face of marketing forever", available at: https://www.bcg.com/publications/2014/marketing-centerconsumer-customer-insight-how-millennials-changingmarketing-forever.aspx\#chapter1 (accessed 20 January 2014).

[5] Dach, L., and Allmendinger, K. (2014), "Sustainability in corporate communications and its influence on consumer awareness and perceptions: A study of H\&M and Primark", Procedia-Social and Behavioral Sciences, Vol. 130, pp. 409418.

[6] Eckhardt, G. M., Belk, R., and Devinney, T. M. (2010), "Why don't consumers consume ethically?, Journal of Consumer Behaviour, Vol. 9 No. 6, pp. 426-436.

[7] Ertekin, Z. O., and Atik, D. (2015), "Sustainable markets motivating factors, barriers, and remedies for mobilization of slow fashion", Journal of Macromarketing, Vol. 35 No. 1, pp. 53-69.

[8] Fletcher, K. (2010), "Slow fashion: An invitation for systems change", Fashion Practice, Vol. 2, pp. 259-266.

[9] Fornell, C. and Larcker, D. F. (1981), "Evaluating structural equation models with unobservable variables and measurement error", Journal of Marketing Research, Vol. 18, pp. 39-50.

[10] Gam, H. J. (2011), “Are fashion-conscious consumers more likely to adopt eco-friendly clothing?", Journal of Fashion Marketing and Management, Vol. 15 No. 2, pp. 178-193.

[11] Grail Research. (2010), "Green - the new color of Luxury: Moving to a sustainable future", available at: www.grailresearch.com/pdf/ContenPodsPdf/2010-Dec-GrailResearch-Green-The-New-Color-of-Luxury.pdf (accessed 22 March 2011).

[12] Hackett, K. (2016), "What H\&M doesn't want you to be 'conscious' about", Huffington Post, available at: $\mathrm{http}: / /$ www.huffingtonpost.com/entry/what-hm-doesnt-wantyou-to-be-conscious-about_us_581252a3e4b09b190529c1fe (accessed 30 October 2016).

[13] Henninger, C. E., Alevizou, P. J. and Oates, C. J. (2016). "What is sustainable fashion?", Journal of Fashion Marketing and Management, Vol. 20 No. 4, pp.400-416.

[14] Hennigs, N. , Wiedmann, K. P. , Klarmann, C., and Behrens, S. (2013), "Sustainability as part of the luxury essence: Delivering value through social and environmental excellence", Journal of Corporate Citizenship, Vol. 52, pp. 25-35.

[15] Hill, J. , and Lee, H. H. (2012), "Young generation Y consumers' perceptions of sustainability in the apparel industry", Journal of Fashion Marketing and Management, Vol. 16 No. 4, pp. 477-491. 
[16] Hodal, K. (2018), "Abuse is daily reality for female garment workers for Gap and H\&M, says report", available at: https://www.theguardian.com/global-

development/2018/jun/05/female-garment-workers-gap-hmsouth-asia (accessed 6 June 2018).

[17] Ivan, C. M., Mukta, R., Sudeep, C., and Burak, C. (2016), "Long-term sustainable sustainability in luxury. Where else?", In Handbook of Sustainable Luxury Textiles and Fashion (pp. 17-34). Springer, Singapore.

[18] Joergens, C. (2006), "Ethical fashion: Myth or future trend?", Journal of Fashion Marketing and Management, Vol. 10 No. 3, pp. 360-371.

[19] Joy, A. (2015), "Fast fashion, luxury brands, and sustainability", The European Financial Review, available at: http://www.europeanfinancialreview.com/?p=4589 (accessed 25 June 2015).

[20] Joy, A., Sherry, J. F., Venkatesh, A., Wang, J., and Chan, R. (2012), "Fast fashion, sustainability, and the ethical appeal of luxury brands", Fashion Theory, Vol. 16 No. 3, pp. 273-295.

[21] Jung, S., and Jin, B. (2014), "A theoretical investigation of slow fashion: Sustainable future of the apparel industry", International Journal of Consumer Studies, Vol. 38 No. 5, pp. 510-519.

[22] Jung, S., and Jin, B. (2016), "From quantity to quality: Understanding slow fashion consumers for sustainability and consumer education", International Journal of Consumer Studies, Vol. 40, pp. 410-421.

[23] Kim, H., Choo, H. J., and Yoon, N. (2013), "The motivational drivers of fast fashion avoidance", Journal of Fashion Marketing and Management, Vol. 17 No. 2, pp. 243-260.

[24] Lam, S. (2017), "Why India and China may be the solution to the world's fast fashion crisis", Forbes, available at: https://www.forbes.com/sites/lamsharon/2017/09/22/whyindia-and-china-may-be-the-solution-to-the-worlds-fastfashion-crisis/\#69d421f2104f (accessed 27 September 2017).

[25] LaRocca, D. (2014), "Brunello Cucinelli: A humanistic approach to luxury, philanthropy, and stewardship", Journal of Religion and Business Ethics, Vol. 3 No. 1, pp. 1-26.

[26] Luchs, M. G., Phipps, M., and Hill, T. (2015), "Exploring consumer responsibility for sustainable consumption", Journal of Marketing Management, Vol. 31 No. 13-14, pp. 1449-1471.

[27] Marsh, H. W., and Hocevar, D. (1985), “The application of confirmatory factor analysis to the study of self-concept: First and higher order factor structures and their invariance across age groups", Psychological Bulletin, Vol. 97, pp. 562-582.

[28] McDonagh, P. \& Prothero, A. (2014). Sustainability marketing research: Past, present and future. Journal of Marketing Management, 30 (11-12), 1186-1219.

[29] McDonald, S., Oates, C. J., Alevizou, P. J., Young, C. W., and Hwang, K. (2012), "Individual strategies for sustainable consumption", Journal of Marketing Management, Vol. 28 No. 3-4, pp. 445-468.
[30] McNeill, L., and Moore, R. (2015), "Sustainable fashion consumption and the fast fashion conundrum: Fashionable consumers and attitudes to sustainability in clothing choice", International Journal of Consumer Studies, Vol. 39 No. 3, pp. 212-222.

[31] Morgan, L. R., and Birtwistle, G. (2009), "An investigation of young fashion consumers' disposal habits", International Journal of Consumer Studies, Vol. 33 No. 2, pp. 190-198.

[32] Niinima"ki, K. (2010), "Eco-clothing, consumer identity and ideology, "Sustainable Development, Vol. 18 No. 3, pp. 150162 .

[33] O'Neill, S. (2017), “Transparency as Disruptor in Retail Brand Storytelling", available at: https://www.skyword.com/contentstandard/storytelling/transp arency-as-disruptor-in-retail-brand-storytelling/ (accessed 6 June 2018).

[34] Park, H., and Kim, Y. K. (2016), "An empirical test of the triple bottom line of customer-centric sustainability: The case of fast fashion", Fashion and Textiles, Vol. 3 No. 1, pp. 25-43.

[35] Peattie, K. (2001), "Golden goose or wild goose? The hunt for the green consumer", Business Strategy and the Environment, Vol., 10, pp. 187-199.

[36] Pookulangara, S. and Shephard, A. (2013), "Slow fashion movement: understanding consumer perceptions - an exploratory study", Journal of Retailing and Consumer Services, Vol. 20 No. 2, pp. 200-206.

[37] Prothero, A., Dobscha, S., Freund, J., Kilbourne, W. E., Luchs, M. G., Ozanne, L. K., \& Thøgersen, J. (2011). Sustainable consumption: Opportunities for consumer research and public policy. Journal of Public Policy \& Marketing, 30(1), 31-38.

[38] Sadachar, A., Feng, F., Karpova, E. E., and Manchiraju, S. (2016), "Predicting environmentally responsible apparel consumption behavior of future apparel industry professionals: The role of environmental apparel knowledge, environmentalism and materialism", Journal of Global Fashion Marketing, Vol. 7 No. 2, pp. 76-88.

[39] Scaraboto, D., and Fischer, E. (2013), "Frustrated fatshionistas: An institutional theory perspective on consumer quests for greater choice in mainstream markets", Journal of Consumer Research, Vol. 39 No. 6, pp. 1234-1257.

[40] Sweeny, G. (2015), "Fast fashion is the second dirtiest industry in the world, next to big oil", EcoWatch, available at: https://www.ecowatch.com/fast-fashion-is-the-second-dirtiestindustry-in-the-world-next-to-big--1882083445.html (accessed 25 August 2015).

[41] Watson, M. Z., and Yan, R. N. (2013), "An exploratory study of the decision processes of fast versus slow fashion consumers", Journal of Fashion Marketing and Management, Vol. 17 No. 2, pp. 141-159.

[42] Wicker, A. (2016), "Fast fashion is creating an environmental crisis", Newsweek, available at: http://www.newsweek.com/2016/09/09/old-clothes-fashionwaste-crisis-494824.html (accessed 12 September 2016). 